\title{
Analisis Faktor-Faktor yang Berpengaruh terhadap Indeks Prestasi Mahasiswa Program Diploma Pelayaran Universitas Hang Tuah
}

\author{
Faulina Khusniawati \\ Universitas Hang Tuah Surabaya \\ Jl. Arief Rachman Hakim No. 150 Telp. (031) 5945864 Surabaya 60111 \\ e-mail: faulina.khusniawati@hangtuah.ac.id
}

\begin{abstract}
ABSTRAK
Indeks Prestasi (IP) adalah nilai kredit rata-rata yang merupakan satuan nilai akhir yang menggambarkan nilai proses belajar mengajar tiap semester. Terdapat beberapa faktor yang mempengaruhi indeks prestasi (IP), khususnya pada mahasiswa Program Diploma Pelayaran Universitas Hang Tuah Surabaya. Dengan metode analisis faktor diperoleh empat faktor yang mempengaruhi indeks prestasi mahasiswa Program Diploma Pelayaran dengan nilai tertinggi hingga terendah ialah Faktor Perhatian, Motivasi dan Cara pengajaran yang meliputi variabel perhatian orang tua, variabel motivasi, variabel cara pengajaran dosen, kemudian Faktor kedua ialah Faktor Lingkungan Belajar dan Kesehatan yang meliputi variabel fasilitas belajar, variabel kesehatan, variabel gaya dan cara belajar mahasiswa, serta variabel suasana tempat tinggal dan Faktor ketiga ialah Faktor Lingkungan Kampus dan Kondisi Ekonomi yang meliputi variabel lingkungan kampus, variabel ekonomi dan variabel kemampuan sosialisasi.
\end{abstract}

Kata kunci : analisis faktor, faktor internal, faktor eksternal, indeks prestasi.

\begin{abstract}
Achievement Index is the average credit score which is the final grade unit that describes the value of teaching and learning process each semester. There are several factors that affect the achievement index, especially for students of the Hang Tuah University Surabaya Sailing Diploma Program. With the factor analysis method, four factors that affect the student achievement index of the Sailing Diploma Program with the highest to lowest scores are the Factors of Attention, Motivation and Ways of teaching which include parents' attention variables, motivation variables, lecturer teaching methods, then the second Factor is the Learning Environment Factor and Health which includes learning facility variables, health variables, student style and learning styles, as well as residential atmosphere variables and the third factor is Campus Environment Factors and Economic Conditions which include campus environment variables, economic variables and socialization ability variables.
\end{abstract}

Keywords : internal factor, external factor, achievement index, factor analysis.

\section{PENDAhuluan}

Sebagai tolok ukur bahwa proses pendidikan yang diselenggarakan tersebut berhasil atau tidaknya, dapat dilihat dari prestasi anak didik. Pada Perguruan Tinggi untuk melihat keberhasilan seorang mahasiswa, dapat diketahui dengan nilai Indeks Prestasi (IP). Indeks Prestasi (IP) adalah nilai kredit rata-rata yang merupakan satuan nilai akhir yang menggambarkan nilai proses belajar mengajar tiap semester atau dapat diartikan juga sebagai besaran atau angka yang menyatakan prestasi keberhasilan dalam proses belajar mengajar mahasiswa pada satu semester. Mahasiswa yang memperoleh indeks prestasi tinggi meng- indikasikan bahwa mahasiswa tersebut mampu mengikuti kuliah dengan baik dan sebaliknya semakin rendah indeks prestasi yang diperoleh menunjukkan bahwa mahasiswa tersebut tidak mampu mengikuti kuliah dengan baik.

Indeks Prestasi dibedakan menjadi Indeks Prestasi Semester (IPS) dan Indeks Prestasi Kumulatif (IPK). IP semester adalah indeks prestasi yang perhitungannya berdasarkan mata kuliah yang ditempuh selama satu semester tertentu. Indeks Prestasi Kumulatif (IPK) adalah indeks prestasi mahasiswa yang perhitungannya berdasarkan seluruh mata kuliah yang telah ditempuh. 
Tabel 1. Ketentuan Predikat Kelulusan

\begin{tabular}{|l|l|}
\hline \multicolumn{1}{|c|}{ IP } & \multicolumn{1}{c|}{ Predikat } \\
\hline 4,00 & Summa Cumlaude \\
\hline $3,51-3,99$ & Cumlaude \\
\hline $2,76-3,50$ & Sangat Memuaskan \\
\hline $2,00-2,75$ & Memuaskan \\
\hline
\end{tabular}

Pada dasarnya ada banyak manfaat atau benefit yang didapat mahasiswa dengan memperoleh indeks prestasi yang baik setiap semesternya. Benefit yang didapat ketika mahasiswa mampu memperoleh indeks prestasi yang tinggi antara lain dapat mempercepat masa kuliahnya, memeroleh beasiswa bahkan sangat memungkinkan bagi mahasiswa pelayaran memudahkan mendapatkan pekerjaan pada perusahaan pelayaran dengan cepat seusai lulus kuliah, karena di era globalisasi ini banyak perusahaan yang merekrut dengan mencari calon pegawai yang memenuhi syarat dan ketentuan yang di tetapkan perusahaan, salah satunya adalah nilai indeks prestasi kumulatif yang harus memenuhi nilai minimal tertentu.

Berdasarkan latar belakang mahasiswa yang beragam serta banyaknya faktor-faktor lain dalam keseharian mereka sebagai seorang mahasiswa, maka sangat mungkin indeks prestasi yang dicapai mahasiswa dipengaruhi oleh berbagai faktor, baik faktor internal maupun eksternal. Faktor-faktor yang mempengaruhi hasil belajar terbagi menjadi 2 yaitu faktor internal dan faktor eksternal (Anni, 2004).

1. Faktor internal, yang mencakup aspek fisik, misalnya kesehatan organ tubuh, aspek psikis, misalnya intelektual, emosional, motivasi, dan aspek sosial, misalnya kemampuan bersosialisasi dengan lingkungan.

2. Faktor eksternal, misalnya variasi dan derajat kesulitan materi yang dipelajari, tempat belajar, iklim, suasana lingkungan, budaya belajar masyarakat dan sebagainya.

Faktor-faktor yang mempengaruhi perolehan indeks prestasi mahasiswa merupakan salah satu hal yang penting untuk digali, untuk itu perlu diungkap faktor-faktor yang mempengaruhi perolehan nilai indeks prestasi mahasiswa. Oleh karena itu pada penelitian ini bertujuan untuk mengetahui faktor-faktor yang berpengaruh terhadap indeks prestasi mahasiswa khususnya mahasiswa di Program Diploma Pelayaran Universitas Hang Tuah Surabaya.

\section{METODE PENELITIAN}

\subsection{Lokasi Penelitian}

Pada penelitian ini untuk memperoleh dan mengumpulkan data, peneliti melakukan penelitian pada Program Diploma Pelayaran Universitas hang Tuah Surabaya.

\subsection{Sumber Data}

Dalam penelitian ini, data yang digunakan adalah data primer yang merupakan data kuisioner mahasiswa aktif tahun ajaran 2018/2019 dan mahasiswa tahun ajaran 2017/2018 berjumlah 100 mahasiswa. Data primer adalah data yang diperoleh secara langsung dari responden dengan menggunakan kuesioner atau daftar pertanyaan yang telah disusun berdasarkan variabel-variabel yang diteliti. Data tersebut berupa jawaban dari responden.

Teknik pengumpulan data yang digunakan dalam penelitian ini adalah penyebaran kuesioner kepada responden dengan mengajukan pertanyaan yang telah disusun untuk membantu responden dalam memberikan jawaban. Pengukuran variabel dalam penelitian ini menggunakan skala likert 5 poin dimana masing-masing pertanyaan diberi skor 1 sampai dengan 5. Rentang skala dimulai 1 sampai 5, dimana angka 1 menunjukkan "sangat tidak setuju" (berarti pendapat responden sama sekali tidak sesuai dengan pernyataan dalam kuesioner) sampai dengan angka 5 yang berarti "sangat setuju" (berarti pendapat responden sangat sesuai dengan pernyataan dalam kuesioner). Sedangkan angka 3 berarti "ragu-ragu" menunjukkan bahwa responden tidak mempunyai pendapat atas pernyataan dalam kuesioner atau responden memang memiliki jawaban netral atas pernyataan dalam kuesioner tersebut.

\subsection{Variabel Penelitian}

Variabel yang digunakan dalam penelitian ini merupakan variabel prediktor, sebagai berikut.

1. Variabel prediktor $(x)$ yang digunakan dalam penelitian ini merupakan faktor-faktor yang berpengaruh terhadap Indeks Prestasi Mahasiswa Fakultas Program Diploma Pelayaran Universitas Hang Tuah. Variabel prediktor yang terpilih adalah sebagai berikut.

Tabel 2. Variabel Penelitian

\begin{tabular}{|c|l|c|}
\hline $\begin{array}{c}\text { Variabel } \\
\text { independen }\end{array}$ & \multicolumn{1}{|c|}{ Keterangan } & Skala \\
\hline$x_{1}$ & $\begin{array}{l}\text { Gaya dan cara } \\
\text { belajar mahasiswa }\end{array}$ & Ordinal \\
\hline$x_{2}$ & Fasilitas Belajar & Ordinal \\
\hline$x_{3}$ & Motivasi pengajaran & Ordinal \\
\hline$x_{4}$ & $\begin{array}{l}\text { Cara } \\
\text { dosen }\end{array}$ \\
\hline$x_{5}$ & Lingkungan kampus & Ordinal \\
\hline$x_{6}$ & $\begin{array}{l}\text { Suasana tempat } \\
\text { tinggal }\end{array}$ & Ordinal \\
\hline
\end{tabular}


Tabel 2. Variabel Penelitian (Lanjutan)

\begin{tabular}{|c|l|c|}
\hline $\begin{array}{c}\text { Variabel } \\
\text { independen }\end{array}$ & \multicolumn{1}{|c|}{ Keterangan } & Skala \\
\hline$x_{7}$ & $\begin{array}{l}\text { Kemampuan } \\
\text { sosialisasi }\end{array}$ & Ordinal \\
\hline$x_{8}$ & $\begin{array}{l}\text { Kondisi keuangan / } \\
\text { ekonomi }\end{array}$ & Ordinal \\
\hline$x_{9}$ & $\begin{array}{l}\text { Perhatian orang tua } \\
\text { / saudara }\end{array}$ & Ordinal \\
\hline$x_{10}$ & Kesehatan & Ordinal \\
\hline
\end{tabular}

\subsection{Langkah-langkah Penelitian}

1. Membagi data sebanyak 2 bagian, yaitu data training dan data testing masing-masing . Data training digunakan untuk membangun model dan data testing diambil $30 \%$ dari data training yang digunakan untuk validasi data dan melihat kemampuan model dalam menduga.

2. Melakukan uji validitas dan reliabilitas pada data

3. Melakukan proses inti pada analisis faktor, yaitu faktoring, atau menurunkan satu atau lebih faktor dari variabel-variabel yang telah lolos pada uji variabel sebelumnya.

4. Mendapatkan faktor-faktor yang telah terbentuk

5. Mengelompokkan faktor berdasarkan nilai korelasi tertinggi

6. Menginterpretasikan atas masing-masing faktor yang telah terbentuk.

Terdapat 3 poin utama dalam metode statistika ini, yakni:

1. Uji Validitas

Validitas mempunyai arti sejauh mana ketepatan dan kecermatan suatu instrumen pengukur dalam melakukan fungsi ukurnya (Azwar, 1996). Suatu item dikatakan valid apabila nilai koefisiennya (pada output SPSS, dapat dilihat pada kolom corrected Item-Total Correlation) 0,300. Corrected Item-Total Correlation adalah korelasi antara suatu variabel dengan total tanpa memasukkan nilai variabel tersebut. Pada uji validitas disarankan agar responden untuk ujicoba minimal 30 orang. Dengan jumlah minimal 30 orang, distribusi skor (nilai) akan lebih mendekati kurva normal. Pada uji validitas ini peneliti menggunakan Corrected Item- Total Correlation. Mengenai jumlah subjek yang dilibatkan dalam sebuah proses uji coba, tidak pernah dibakukan secara jelas. Pendapat yang banyak digunakan adalah minimal 30 orang (Guilford, 1956).

\section{Uji Reliabilitas}

Uji reliabilitas digunakan untuk mengetahui konsistensi alat ukur, apakah alat pengukur yang digunakan dapat diandalkan dan tetap konsisten jika pengukuran tersebut diulang. Ada beberapa metode pengujian reliabilitas diantaranya metode tes ulang, formula belah dua dari Spearman-Brown, formula Rulon, formula Flanagan, Cronbach's Alpha, metode formula KR-20, KR-21, dan metode Anova Hoyt. Dalam program SPSS akan dibahas untuk uji yang sering digunakan penelitian mahasiswa adalah dengan menggunakan metode Alpha (Cronbach's). Metode alpha sangat cocok digunakan pada skor berbentuk skala (misal 1-4, 15) atau skor rentangan (misal 0-20, 0-50). Metode alpha dapat juga digunakan pada skor dikotomi (0 dan 1) dan akan menghasilkan perhitungan yang setara dengan menggunakan metode KR-20 dan Anova Hoyt.

Uji Reliabilitas dilakukan dengan uji Alpha Cronbach. Rumus Alpha Cronbach sebagai berikut:

$\propto=\left(\frac{K}{K-1}\right)\left(\frac{s_{r}^{2}-\sum s_{i}^{2}}{s_{x}^{2}}\right)$

Keterangan :

$\propto \quad$ : Koefisien realibilitas Alpha Cronbach

$K \quad$ : Jumlah item pertanyaan yang diuji

$\sum s_{i}{ }^{2} \quad$ : Jumlah varians skor item

$s_{x}{ }^{2} \quad$ : Varians skor-skor tes (seluruh item K)

Jika alpha > 0,90 maka reliabilitas sempurna, jika alpha antara 0,70 - 0,90 maka reliabilitas tinggi, jika alpha antara $0,50-0,70$ maka reliabilitas moderat dan jika alpha $<0,50$ maka reliabilitas rendah.

\section{Analisis Faktor}

Analisis faktor adalah salah satu keluarga analisis multivariate yang bertujuan untuk meringkas atau mereduksi variable amatan secara keseluruhan menjadi beberapa variable atau dimensi baru, akan tetapi variabel atau dimensi baru yang terbentuk tetap mampu merepresentasikan variable utama. Asumsi mendasar yang harus digarisbawahi dalam analisis faktor adalah bahwa variable-variabel yang dianalisis memiliki keterkaitan atau saling berhubungan karena analisis factor berusaha untuk mencari common dimension (kesamaan dimensi) yang mendasari variablevariabel tersebut. Selain itu, analisis faktor juga berfungsi untuk mereduksi sejumlah variabel asal yang jumlahnya banyak menjadi sejumlah variabel baru yang jumlahnya lebih sedikit dari variabel asal, dan variabel baru tersebut dinamakan faktor atau variabel laten atau konstruk atau variabel bentukan. 
Statistik kunci yang relevan dengan analisis faktor adalah sebagai berikut :

1. Bartlett's test of sphericity yaitu suatu uji statistik yang dipergunakan untuk menguji hipotesis bahwa variabel tidak saling berkorelasi (uncorrelated) dalam populasi. Dengan perkataan lain matriks korelasi populasi merupakan matriks identitas (identity matrix). Statistik uji bartlett adalah sebagai berikut :

$$
\chi^{2}=-\left[(N-1)-\frac{(2 p+5)}{6}\right] \ln |R|
$$

dengan derajat kebebasan atau $\mathrm{df}=\mathrm{p}(\mathrm{p}-1) / 2$ Keterangan :

$$
\begin{array}{ll}
N & =\text { jumlah observasi } \\
\mathrm{p} & =\text { jumlah variabel } \\
|\mathrm{R}| & =\text { determinan matriks korelasi }
\end{array}
$$

2. Kaiser-Meyer-Olkin (KMO) merupakan suatu ndeks yang dipergunakan untuk meneliti ketepatan analisis faktor. Analisis faktor dikatakan tepat apabila nilai KMO berkisar antara 0,5 - 1,0 dan sebaliknya jika nilai KMO kurang dari 0,5 berarti analisis faktor tidak tepat.

$$
K M O=\frac{\sum \sum_{i \neq j} r_{i j}^{2}}{\sum \sum_{i \neq j} r_{i j}^{2}+\sum \sum_{i \neq j} a_{i j}^{2}}
$$

Keterangan :

$r_{i k}^{2}=$ koefisien korelasi sederhana antara variabel ke-i dan ke-k

$a_{i k}^{2}=$ koefisien korelasi parsial antara variabel ke-i dan ke-k

3. Measure of Sampling Adequacy (MSA) yaitu suatu indeks perbandingan antara koefisien korelasi parsial untuk setiap variabel. MSA digunakan untuk mengukur kecukupan sampel.

$\operatorname{MSA}_{i}=\frac{\sum_{i \neq k} r_{i k}^{2}}{\sum_{i \neq k} r_{i k}^{2}+\sum_{i \neq k} a_{i k}^{2}}$

$r_{i k}^{2}=$ koefisien korelasi sederhana antara variabel ke-i dan ke-k

$a_{i k}^{2}=$ koefisien korelasi parsial antara variabel ke-i dan ke-k

\section{Hasil dan Pembahasan}

Hasil perhitungan dan pengolahan data diperoleh dari bantuan hasil perhitungan dan pengolahan program computer SPSS (Statistic Program for Social Solution) versi 20. Adapun hal yang menjadi bahan pertimbangan dari penggunaan program SPSS adalah sebagai berikut :

a) Program SPSS merupakan program komputer, sehingga dalam perhitungan dan pengolahan, hasilnya dapat lebih dipertanggungjawabkan dan lebih akurat.

b) Proses perhitungan dan pengolahan datanya lebih dari cepat daripada perhitungan manual, sehingga dapat mempersingkat waktu pengolahan dan perhitungan.

1. Uji Validitas

Pada penelitian ini uji validitas dilakukan dengan menghitung korelasi skor masing-masing butir pertanyaan dengan skor total seluruh butir pertanyaan dalam suatu variable. Perhitungan korelasi yang digunakan adalah korelasi product moment dari person (Ghozali, 2001), kriterianya adalah sebagai berikut :

a) Suatu butir adalah valid jika terdapat korelasi yang signifikan yang ditunjukkan $\alpha=0,05$ antara butir pertanyaan yang diukur validitasnya dengan skor total butir pertanyaan.

b) Suatu butir pertanyaan adalah tidak valid jika nilai signifikansinya melebihi $\alpha=0,05$ atau tidak terdapat korelasi yang signifikan antara butir pertanyaan tersebut dengan skor total seluruh butir pertanyaan.

Hasil uji validitas disajikan pada Tabel 3 berikut.

Tabel 3. Hasil Uji Validitas

\begin{tabular}{|l|l|l|l|}
\hline Variabel & $\begin{array}{l}\text { Nilai } \\
\text { Korelasi }\end{array}$ & $\begin{array}{l}\text { Nilai } \\
\text { Signifikansi }\end{array}$ & Keterangan \\
\hline $\mathrm{X}_{1}$ & 0,822 & 0,00 & Valid \\
\hline $\mathrm{X} 2$ & 0,855 & 0,00 & Valid \\
\hline $\mathrm{X} 3$ & 0,903 & 0,00 & Valid \\
\hline $\mathrm{X} 4$ & 0,850 & 0,00 & Valid \\
\hline $\mathrm{X} 5$ & 0,852 & 0,00 & Valid \\
\hline $\mathrm{X} 6$ & 0,929 & 0,00 & Valid \\
\hline $\mathrm{X} 7$ & 0,910 & 0,00 & Valid \\
\hline $\mathrm{X} 8$ & 0,813 & 0,00 & Valid \\
\hline $\mathrm{X} 9$ & 0,837 & 0,00 & Valid \\
\hline $\mathrm{X} 10$ & 0,834 & 0,00 & Valid \\
\hline
\end{tabular}

Berdasarkan Tabel 3 di atas dapat diketahui bahwa seluruh butir item pertanyaan memiliki nilai signifikansi korelasi lebih kecil daripada 0,05 dengan demikian dapat dikatakan bahwa seluruh butir pertanyaan adalah valid. 
2. Uji Reliabilitas

Suatu kuisioner dikatakan reliabel atau handal jika jawaban seseorang terhadap peryataan adalah konsisten atau stabil dari waktu ke waktu. Suatu konstruk atau variabel dikatakan reliabel jika memberikan nilai cronbach alpha >0,6. Hasil uji reliabilitas dapat dilihat pada tabel di bawah ini.

Tabel 4. Hasil Uji Reliabilitas

\begin{tabular}{|c|c|c|}
\hline Variabel & Nilai alpha & Ket \\
\hline All Variabel & 0,961 & Reliabel \\
\hline
\end{tabular}

Berdasarkan Tabel 4 diatas terlihat bahwa nilai alpha untuk semua variabel lebih besar daripada 0,6 , oleh karena itu semua variabel dinyatakan reliabel.

\section{Analisis Faktor}

Hasil pengolahan menunjukkan hasil uji KMO (Kaiser Meyer Olkin) lebih besar dari 0,05 yakni sebesar 0,806 dan hasil uji Bartlett atau biasa disebut sebagai Bartlett's test of sphericity nilainya lebih kecil dari 0,05 yakni sebesar 0,000 dengan kata lain nilainya signifikan.

Tabel 5. Hasil Pengukuran KMO dan Bartlett's test of sphericity

\begin{tabular}{|l|c|}
\hline Kaiser-Mayer-Olkin (KMO) & 0,806 \\
\hline Bartlett's test of sphericity sig. & 0,000 \\
Approximation Chi-square & 420,5 \\
Df & 45 \\
\hline
\end{tabular}

Hasil pengolahan berikutnya adalah informasi tentang MSA (Measure of Sampling Adequacy). Nilai MSA pada kesepuluh variabel penelitian lebih besar dari 0,5. Hal ini menunjukkan bahwa semua variabel layak untuk dianalisis dan pengolahan data dapat dilanjutkan dengan analisis faktor.

Tabel 6. Hasil Pengukuran MSA

\begin{tabular}{|l|l|c|}
\hline No & $\begin{array}{l}\text { Variabel } \\
\text { penelitian }\end{array}$ & $\begin{array}{c}\text { Anti image } \\
\text { Correlation }\end{array}$ \\
\hline 1 & $\mathrm{X}_{1}$ & 0,780 \\
\hline 2 & $\mathrm{X}_{2}$ & 0,748 \\
\hline 3 & $\mathrm{X}_{3}$ & 0,793 \\
\hline 4 & $\mathrm{X}_{4}$ & 0,867 \\
\hline 5 & $\mathrm{X}_{5}$ & 0,811 \\
\hline 6 & $\mathrm{X}_{6}$ & 0,899 \\
\hline 7 & $\mathrm{X}_{7}$ & 0,731 \\
\hline 8 & $\mathrm{X}_{8}$ & 0,790 \\
\hline 9 & $\mathrm{X}_{9}$ & 0,782 \\
\hline 10 & $\mathrm{X}_{10}$ & 0,851 \\
\hline
\end{tabular}

Hasil pengolahan selanjutnya adalah tabel communalities, tabel communalities ini menu njukkan nilai variabel yang diteliti apakah mampu untuk menjelaskan faktor atau tidak. Variabel dianggap mampu menjelaskan faktor jika nilai extraction lebih besar dari 0,50. Tabel communalities dapat dilihat pada Tabel 7.

Tabel 7. Tabel Communalities

\begin{tabular}{|l|l|c|}
\hline No & \multicolumn{1}{|c|}{$\begin{array}{c}\text { Variabel } \\
\text { penelitian }\end{array}$} & Nilai extraction \\
\hline 1 & $\mathrm{X}_{1}$ & 0,671 \\
\hline 2 & $\mathrm{X}_{2}$ & 0,715 \\
\hline 3 & $\mathrm{X}_{3}$ & 0,673 \\
\hline 4 & $\mathrm{X}_{4}$ & 0,511 \\
\hline 5 & $\mathrm{X}_{5}$ & 0,576 \\
\hline 6 & $\mathrm{X}_{6}$ & 0,660 \\
\hline 7 & $\mathrm{X}_{7}$ & 0,783 \\
\hline 8 & $\mathrm{X}_{8}$ & 0,744 \\
\hline 9 & $\mathrm{X}_{9}$ & 0,847 \\
\hline 10 & $\mathrm{X}_{10}$ & 0,644 \\
\hline
\end{tabular}

Berdasarkan Tabel 7 di atas, diketahui nilai extraction untuk semua variabel adalah lebih besar dari 0,50. Dengan demikian dapat disimpulkan bahwa semua variabel dapat dipakai untuk menjelaskan faktor. Guna menentukan seberapa banyak faktor yang mungkin terbentuk dapat dilihat pada tabel Total Variance Explained sebagai berikut: (Santoso, 2006)

Tabel 8. Hasil Rekapitulasi Faktor

\begin{tabular}{|l|c|c|c|}
\hline \multirow{2}{*}{ Faktor } & \multicolumn{3}{|c|}{ Eigen value } \\
\cline { 2 - 4 } & Eigen value & \% Variansi & $\begin{array}{c}\text { \% Variansi } \\
\text { kumulatif }\end{array}$ \\
\hline 1 & 4,593 & 45,925 & 45,925 \\
\hline 2 & 1,194 & 11,938 & 57,863 \\
\hline 3 & 1,037 & 10,367 & 68,230 \\
\hline 4 & 0,825 & 8,255 & 76,485 \\
\hline 5 & 0,631 & 6,307 & 82,791 \\
\hline 6 & 0,474 & 4,744 & 87,536 \\
\hline 7 & 0,380 & 3,802 & 91,338 \\
\hline 8 & 0,376 & 3,761 & 95,099 \\
\hline 9 & 0,276 & 2,762 & 97,861 \\
\hline 10 & 0,214 & 2,139 & 100,000 \\
\hline
\end{tabular}

Pada kolom Eigen Value yang pada program ditentukan nilainya 1 . Varians bisa diterangkan oleh oleh faktor 1 adalah 4,593/10 x 100\%= $45,925 \%$. Sementara oleh faktor 2 sebesar 1,194/10 $\mathrm{x} 100 \%=11,938 \%$, dan oleh faktor 3 sebesar $1,037 / 10 \times 100 \%=10,367 \%$. Dan, total ketiga faktor akan mampu menjelaskan variabel sebesar $45,925 \%+11,938 \%+10,367=68,230 \%$ pada Tabel 9. Dengan demikian, karena nilai Eigenvalues yang ditetapkan 1, maka nilai Total 
yang akan diambil adalah yang > 1 yaitu component 1 dan 2 dan 3 .

Tabel 9. Hasil Rekapitulasi Faktor Setelah Rotasi

\begin{tabular}{|l|c|c|}
\hline \multirow{2}{*}{ Faktor } & \multicolumn{2}{|c|}{ Variansi (setelah rotasi) } \\
\cline { 2 - 3 } & $\%$ Variansi & $\%$ Variansi kumulatif \\
\hline 1 & 24,072 & 24,072 \\
\hline 2 & 22,557 & 46,630 \\
\hline 3 & 21,600 & 68,230 \\
\hline 4 & - & - \\
\hline 5 & - & - \\
\hline 6 & - & - \\
\hline 7 & - & - \\
\hline 8 & - & - \\
\hline 9 & - & - \\
\hline 10 & - & - \\
\hline
\end{tabular}

Untuk memastikan suatu variabel masuk dalam kelompok faktor yang mana, maka dapat ditentukan dengan melihat nilai korelasi terbesar antara variabel dengan faktor yang terbentuk pada tabel Rotated Component Matrix sebagai berikut:

Tabel 10. Hasil Rotated Faktor Loading

\begin{tabular}{|l|c|c|c|}
\hline \multirow{2}{*}{$\begin{array}{c}\text { Variabel } \\
\text { Penelitian }\end{array}$} & \multicolumn{3}{|c|}{ Faktor } \\
\cline { 2 - 4 } & 1 & 2 & 3 \\
\hline $\mathrm{X}_{1}$ & 0,513 & 0,632 & $-0,091$ \\
\hline $\mathrm{X}_{2}$ & 0,160 & 0,816 & 0,155 \\
\hline $\mathrm{X}_{3}$ & 0,698 & 0,227 & 0,366 \\
\hline $\mathrm{X}_{4}$ & 0,500 & 0,385 & 0,337 \\
\hline $\mathrm{X}_{5}$ & 0,248 & 0,334 & 0,635 \\
\hline $\mathrm{X}_{6}$ & 0,524 & 0,594 & 0,179 \\
\hline $\mathrm{X}_{7}$ & 0,043 & 0,206 & 0,859 \\
\hline $\mathrm{X}_{8}$ & 0,475 & $-0,068$ & 0,717 \\
\hline $\mathrm{X}_{9}$ & 0,904 & 0,120 & 0,120 \\
\hline $\mathrm{X}_{10}$ & 0,004 & 0,682 & 0,423 \\
\hline
\end{tabular}

Dengan melihat pembahasan di atas, maka kesimpulan yang dapat kita ambil dalam analisis faktor adalah sebagai berikut :

Tabel 11. Hasil analisis faktor

\begin{tabular}{|l|l|}
\hline Faktor & Variabel pendukung \\
\hline 1 & $\mathrm{X}_{3}, \mathrm{X}_{4}, \mathrm{X}_{9}$ \\
\hline 2 & $\mathrm{X}_{1}, \mathrm{X}_{2}, \mathrm{X}_{6}, \mathrm{X}_{10}$ \\
\hline 3 & $\mathrm{X}_{5}, \mathrm{X}_{7}, \mathrm{X}_{8}$ \\
\hline
\end{tabular}

Uraian pada Tabel 11 akan dijelaskan sebagai berikut :

\section{Faktor pertama}

Faktor pertama hasil rotasi faktor didukung oleh 3 variabel. Urutan variabel-variabel tersebut mulai dari nilai bobot paling besar sampai yang paling kecil adalah $\mathrm{X}_{9}, \mathrm{X}_{3}, \mathrm{X}_{4}$ dan Bobot masing-masing variabel pendukung faktor pertama tersebut sesuai dengan tabel berikut.

Tabel 12. Bobot Variabel yang Mendukung Faktor Pertama

\begin{tabular}{|l|l|l|c|}
\hline No & $\begin{array}{l}\text { Variabel } \\
\text { pendukung }\end{array}$ & Nama Variabel & $\begin{array}{l}\text { Bobot } \\
\text { variabel }\end{array}$ \\
\hline 1 & $\mathrm{X}_{9}$ & $\begin{array}{l}\text { Perhatian orang } \\
\text { tua / saudara }\end{array}$ & 0,904 \\
\hline 2 & $\mathrm{X}_{3}$ & Motivasi & 0,698 \\
\hline 3 & $\mathrm{X}_{4}$ & $\begin{array}{l}\text { Cara } \\
\text { pengajaran } \\
\text { dosen }\end{array}$ & 0,500 \\
\hline
\end{tabular}

Dari Tabel 12 di atas, faktor pertama didukung oleh variabel-variabel perhatian orang tua / saudara, motivasi, dan cara pengajaran dosen. Berdasarkan uraian tersebut, faktor pertama layak diberi nama Faktor Perhatian, Motivasi dan Cara pengajaran.

\section{Faktor kedua}

Faktor kedua hasil rotasi faktor didukung oleh 4 variabel. Urutan variabel-variabel tersebut mulai dari nilai bobot paling besar sampai yang paling kecil adalah $\mathrm{X}_{2}, \mathrm{X}_{10}, \mathrm{X}_{1}, \mathrm{X}_{6}$ dan Bobot masingmasing variabel pendukung faktor kedua tersebut sesuai dengan tabel berikut.

Tabel 13. Bobot variabel yang mendukung faktor kedua

\begin{tabular}{|l|l|l|c|}
\hline No & $\begin{array}{l}\text { Variabel } \\
\text { pendukung }\end{array}$ & Nama Variabel & $\begin{array}{l}\text { Bobot } \\
\text { variabel }\end{array}$ \\
\hline 1 & $\mathrm{X}_{2}$ & Fasilitas Belajar & 0,816 \\
\hline 2 & $\mathrm{X}_{10}$ & Kesehatan & 0,682 \\
\hline 3 & $\mathrm{X}_{1}$ & $\begin{array}{l}\text { Gaya dan cara } \\
\text { belajar } \\
\text { mahasiswa }\end{array}$ & 0,632 \\
\hline 4 & $\mathrm{X}_{6}$ & $\begin{array}{l}\text { Suasana tempat } \\
\text { tinggal }\end{array}$ & 0,594 \\
\hline
\end{tabular}

Dari Tabel 13 di atas, faktor kedua didukung oleh variabel-variabel Fasilitas Belajar, Kesehatan, Gaya dan cara belajar mahasiswa dan Suasana tempat tinggal. Berdasarkan uraian tersebut, faktor kedua layak diberi nama faktor lingkungan belajar dan kesehatan

\section{Faktor ketiga}

Faktor ketiga hasil rotasi faktor didukung oleh 3 variabel. Urutan variabel-variabel tersebut mulai dari nilai bobot paling besar sampai yang paling kecil adalah $\mathrm{X}_{5}, \mathrm{X}_{8}, \mathrm{X}_{7}$ dan Bobot masing-masing variabel pendukung faktor ketiga tersebut sesuai 
dengan Tabel 13. Faktor ketiga didukung oleh variabel-variabel Lingkungan kampus, Kondisi keuangan / ekonomi, dan Kemampuan sosialisasi. Berdasarkan uraian tersebut, faktor ketiga layak diberi nama faktor lingkungan kampus dan kondisi ekonomi

Tabel 14. Bobot variabel yang mendukung faktor ketiga

\begin{tabular}{|l|l|l|c|}
\hline No & $\begin{array}{l}\text { Variabel } \\
\text { pendukung }\end{array}$ & Nama Variabel & $\begin{array}{l}\text { Bobot } \\
\text { variabel }\end{array}$ \\
\hline 1 & $\mathrm{X}_{5}$ & $\begin{array}{l}\text { Lingkungan } \\
\text { kampus }\end{array}$ & 0,635 \\
\hline 2 & $\mathrm{X}_{8}$ & $\begin{array}{l}\text { Kondisi } \\
\text { keuangan } \\
\text { ekonomi }\end{array}$ & 0,717 \\
\hline 3 & $\mathrm{X}_{7}$ & $\begin{array}{l}\text { Kemampuan } \\
\text { sosialisasi }\end{array}$ & 0,859 \\
\hline
\end{tabular}

\section{KESIMPULAN DAN SARAN}

Berdasarkan hasil dan pembahasan di atas, maka dapat disimpulkan bahwa :

1. Dari hasil penelitian 100 responden dan 10 variabel penelitian dapat digambarkan variansi kumulatif sebesar 68,230 \% dengan 3 (tiga) faktor hasil ekstraksi yang berpengaruh terhadap perolehan indeks prestasi mahasiswa program diploma pelayaran Universitas Hang Tuah Surabaya. Faktor - faktor tersebut antara lain :

a. Faktor Perhatian, Motivasi dan Cara pengajaran adalah faktor tertinggi pertama dengan nilai eigen value sebesar 4,593

b. Faktor Lingkungan Belajar dan Kesehatan adalah faktor tertinggi kedua dengan nilai eigen sebesar 1,194

c. Faktor Lingkungan Kampus dan Kondisi Ekonomi adalah faktor tertinggi ketiga dengan nilai eigen sebesar 1,037

2. Diharapkan setelah mendapatkan faktor-faktor yang berpengaruh, dapat menjadi informasi bagi mahasiswa maupun pihak fakultas sehingga indeks prestasi mahasiswa Fakultas Program Diploma Pelayaran Universitas Hang Tuah dapat lebih meningkat.

\section{DAFTAR PUSTAKA}

Anni, Catharina Tri. 2004. Psikologi Belajar. Semarang: Unnes Press

Azwar, Saifuddin. 1996. Reliabilitas dan Validitas. Edisi Ketiga. Yogyakarta. Pustaka Pelajar.
Guilford, J.P. 1956. Fundamental Statistic In Psychology and Education. McGraw-Hill: New York

Ghozali, Imam. 2001. Aplikasi Analisis Multivariate dengan program SPSS. Semarang: Badan Penerbit Universitas Diponegoro

Santoso, Singgih. 2006. Seri Solusi Bisnis Berbasis TI: Menggunakan SPSS untuk Statistik Multivariat. Jakarta: Elex Media Komputindo. 